\title{
Study of Needle Stick Injuries among Health Care Workers at a Tertiary Care Hospital
}

\author{
P.R. Lyra, Vivek Hittinahalli", K.T. Sangeetha \\ Department of Microbiology, East Point College of Medical Sciences and Research Centre, \\ Bangalore, Karnataka, India \\ *Corresponding author
}

\section{Keywords}

Needle stick injuries, Health care workers, Gloves, NSI prevention program

Article Info

Accepted:

10 June 2019

Available Online: 10 July 2019

\section{A B S T R A C T}

Needle stick injuries (NSIs) are the injuries that are caused by needles, such as hypodermic needles, blood collection needles, intravenous stylets, and needles used to connect parts of intravenous delivery systems. NSIs are very common and in many instances unavoidable among healthcare providers when they are delivering patient care. Around $75 \%$ of the NSIs in developing countries are not reported. This study aimed to estimate the prevalence and other correlates and attributes of NSIs among healthcare providers in a tertiary care teaching hospital in South India. . An observational prospective study was conducted at a East Point College of Medical Sciences \& Research Centre, Bangalore during a period of January 2017 to December 2018. We analyzed the data of all the HCWs who voluntarily reported injuries by needle stick, sharps such as cannulas, broken vials and splashes on cuts, and mucous membranes by potentially infectious materials such as blood and other body fluids. 48 NSI events were reported during the study period of two years .Among these $36(75 \%)$ were females and $12(25 \%)$ were males. Percutaneous injuries $(45,93.7$ $\%$ ) were more common as compared to mucocutaneous exposures $(3,6.3 \%)$. In our study the highest incidence of needle stick injuries were among the nursing staff $(31.2 \%)$ and nursing students $(27.1 \%)$. Injuries were most commonly reported from wards $(16,33.3 \%)$ followed by emergency department $(11,22.9 \%)$. Majority of the NSI occurred during procedures $(\mathrm{n}=35,73 \%)$. Syringe needles $(41.7 \%)$ were the most common devices leading to NSIs. 22 (45.8\%) of the HCW had completed 3 doses of Hepatitis B vaccination, while $17(35.4 \%)$ had completed 2 doses,8 (16.6\%) had completed the first dose and 1(2.2\%) was unvaccinated. Only $22(45.8 \%)$ of the HCWs were using gloves, at the time of exposure. Cleaning the injury site with running water was the most frequently used first aid measure in over $75 \%$ of the injured HCWs. Source patient could be identified in $39(81.3 \%)$ exposures Establishment of formal reporting mechanisms, immediate reporting of NSIs, and the establishment of a comprehensive NSI prevention program will help in the reduction in the occurrence of NSIs and help in taking immediate remedial action in the form of prophylaxis and treatment.

\section{Introduction}

Needle stick injuries (NSIs) are the injuries that are caused by needles such as hypodermic needles, blood collection needles, intravenous stylets, and needles used to connect parts of intravenous delivery systems ${ }^{1}$. NSIs are very common and in many instances 
unavoidable among healthcare providers when they are delivering patient care. In the healthcare sector, NSIs are one of the most preventable occupational hazards among healthcare providers. $^{2}$ Centers for Disease Control (CDC) of the United States of America estimated that exposure to blood and body fluids by sharps and NSIs affect around three million health workers annually with an estimated occurrence of six million NSIs every year. ${ }^{3}$

The occupational exposures to NSIs are considered to be much higher in the developing world and much of the cases are not even reported. ${ }^{4}$ It is expected that around $75 \%$ of the NSIs in developing countries are not reported 4 Globally, there is gross under- reporting of NSI with the actual incidence of NSIs being much higher than those reported. ${ }^{5}$

Hepatitis B virus (HBV), hepatitis C virus (HCV), and human immunodeficiency virus (HIV) are the most common blood-borne viruses (BBVs) that are transmitted by NSIs. The risk of transmission of $\mathrm{HBV}, \mathrm{HCV}$, and HIV following NSIs is about 3\%-10\%, 3\%, and $0.3 \%$, respectively. ${ }^{6}$

Timely reporting of NSIs has several benefits as it (i) warrants necessary counseling (ii) facilitates initiating early prophylaxis, testing the source status, (iii) helps investigate the cause of exposures and finding out methods including engineering control that would prevent further injuries, and (iv) establishes any legal prerequisites for HCWs reimbursement or compensation. Failure to report NSIs precludes the HCW from receiving post exposure prophylaxis (PEP).Hence this study aimed to estimate the prevalence and other correlates and attributes of NSIs among healthcare providers in a tertiary care teaching hospital in South India.

\section{Materials and Methods}

This observational prospective study was conducted at East Point College of Medical Sciences \& Research Centre, Bangalore during a period of January 2017 to December 2018. We analyzed the data of all the HCWs who voluntarily reported injuries by needlestick, sharps such as cannulas, broken vials and splashes on cuts, and mucous membranes by potentially infectious materials such as blood and other body fluids. Scratches with a minute or no blood oozing following the injury were classified as superficial injury and injuries penetrating through the skin or leading to bleeding wound as deep injury. As a routine practice, we administer a questionnaire to all self-reporting HCWs. The exposed HCWs were asked to fill up a self reporting questionnaire which included information regarding the type of injury, the source of injury (known/unknown), use of personal protective equipment at the time of injury or splashes, what type of work the HCWs does, the severity of the injury, emergency/routine health care, hepatitis B vaccination status, immediate post exposure measures taken like washing of hands, status of source of exposure, and if the HCW was knowing his/her status of HIV, HBV, and HCV positivity. We have an active PEP program with an integrated approach to prevention including awareness raising, teaching, training, protective equipment like heavy duty gloves, banning of recapping, sharps containers, color -coded waste bins, vaccination as well as round the clock sharps and splashes reporting and blood testing facility based on the guidelines of the National AIDS Control Organization of India $(\mathrm{NACO})^{7}$. The standard pro forma for tests as prescribed in the NACO guidelines for each occupational exposure was followed. The serum samples of patients (if known source) from whom the HCWs got exposed, were tested for HIV, HBV, and HCV by rapid test. 
Serum samples from exposed HCWs were also collected and screened for HIV, HBV, and HCV. HCWs who got exposed to seropositive patients were given PEP. For seroconversion, all HCWs under investigation were counseled and advised to get tested again after 3 weeks, 3 months, and finally after 6 months.

\section{Results and Discussion}

48 NSI events were reported during the study period of two years which corresponds to 1.1 NSI events per 1000 inpatient days. All the events were reported voluntarily by the HCWs after the incident occurred. Among these $36(75 \%)$ were females and $12(25 \%)$ were males. Percutaneous injuries $(45,93.7$ $\%)$ were more common as compared to mucocutaneous exposures $(3,6.3 \%)$. Most of the percutaneous injuries $(38,80 \%)$ were superficial. Most common site of injury was hands mainly fingers (98\%).

Evaluation of the kind of activity during which the NSI occurred showed that most occurred during procedures $(n=35,73 \%)$. The most common procedure was blood collection $(\mathrm{n}=18,51.4 \%)$, followed by iv cannulation $(\mathrm{n}=9,25.7 \%) \&$ operative procedures $(\mathrm{n}=8$, $22.9 \%)$

\section{Vaccination status of health-care workers}

$22(45.8 \%)$ of the HCW had completed 3 doses of Hepatitis B vaccination, while 17 (35.4\%) had completed 2 doses, 8 (16.6\%) had completed the first dose and $1(2.2 \%)$ was unvaccinated.

\section{Evaluation of source}

Source patient could be identified in 39 $(81.3 \%)$ exposures. Serological status for three major viral infections (HIV, HBV, and HCV) was unknown in $9(18.7 \%)$ sources.
Two HCW who got exposed to HIV seropositive patient's blood were given PEP and referred to the nearest antiretroviral therapy centre. No seroconversion was seen in any of the exposed HCWs after 6 months.

Knowledge, attitude, behavior, and practices of health-care workers

Insufficient level of knowledge on HIV transmission and the risks after exposure was observed expectedly more in hospital waste disposal staff as compared to doctors and nurses. Only $22(45.8 \%)$ of the HCWs were using gloves, at the time of exposure. Cleaning the injury site with running water was the most frequently used first-aid measure in over $75 \%$ of the injured HCWs. Other measures used for immediate management included cleaning with disinfectants such spirit, soap and squeezing the site.

48 NSI events were reported during the study period of two years which corresponds to 1.1 NSI events per 1000 inpatient days. All the events were reported voluntarily by the HCWs after the incident occurred. Studies done in India showed that the prevalence of NSIs among healthcare workers was between $57 \%$ and $73 \% .^{8,9}$ Various studies done internationally showed different prevalence of NSIs. A study in Pakistan showed that the prevalence of NSIs was $54.2 \%,{ }^{10} 63.3 \%$ in Iran ${ }^{11}$ and $74 \%$ in Saudi Arabia. ${ }^{12}$ This shows that the prevalence of NSIs in our study was much lesser compared with other studies done both in India and internationally. This difference may be due to lack of active surveillance or under- reporting or both since the present study is based on voluntary reporting.

In our study the incidence of needle stick injuries were more common in females than in males. Pournaras et al., ${ }^{13}$ reported a 
considerably higher rate of needle-stick injuries among female health care workers compared to male health care workers. Some studies have reported females HCWs being the most common group to sustain NSI, probably nurses. ${ }^{14,15}$

In our study the highest incidence of needle stick injuries were among the nursing staff $(31.2 \%)$ and nursing students (27.1\%). In a study conducted by Singru et al., ${ }^{16}$ the highest incidence was among nurses (39.63\%), followed by interns (37.34\%), laboratory technicians $(26.92 \%)$, and least among resident doctors $(21.01 \%)$. Evans et al., ${ }^{17}$ in their study in UK reported that the most commonly exposed groups to percutaneous injuries were nurses (45\%) and doctors $(2 \%)$.

Injuries were most commonly reported from wards $(16,33.3 \%)$ followed by emergency department $(11,22.9 \%)$. In emergency wards, most of the time HCWs carry out the procedures on an urgent basis, and the pressure of immediate patient care increases the chances of NSI. However, many studies report operation theaters are the most common site of NSI to occur up to $53.84 \% .^{18 \text {, }}$ ${ }^{19}$ In our study, only $8.3 \%$ of NSI occurred in operation theaters. This difference could be due to the good patient-doctor ratio at this institution in operation theaters.

In our study majority of the NSI occurred during procedures $(n=35,73 \%)$. Recapping and post use disposal of needles have been reported as the most common action during which HCW sustain NSI (34.0-65\%). ${ }^{18,20}$ This denotes increased hazard awareness among HCWs and use of safer needle disposal methods at our institute. In our study the most common procedure during which NSI occurred was blood collection $(n=18$, $51.4 \%)$, followed by iv cannulation $(\mathrm{n}=9$, $25.7 \%) \&$ operative procedures $(n=8,22.9$ $\%)$. This is in contrast to many other studies where stitching was the most common procedure (29-46\%), followed by blood sample collection (19\%) responsible for NSI. $^{14,16,19}$

NSIs were caused by several different devices. In our study, the common type of devices causing NSIs are syringe needles, followed by lancet, intravenous cannula, and suture needle.

Other studies showed that the most common device causing NSIs was the hollow bore needles, followed by suturing needle. ${ }^{21,22,23}$

Of the blood- borne diseases, hepatitis B is not only the most transmissible infection but also the only one that is preventable by vaccination. $^{24}$ Anti- HBV vaccination coverage varies from $18 \%$ in Africa to $77 \%$ in Australia and New Zealand, according to the WHO estimates. ${ }^{25}$ In our study $22(45.8 \%)$ of the HCW had completed 3 doses of Hepatitis $\mathrm{B}$ vaccination, while $17 \quad(35.4 \%)$ had completed 2 doses, $8(16.6 \%)$ had completed the first dose and $1(2.2 \%)$ was unvaccinated.

This partial vaccination status is because infection control committee of our institute took a decision to make the HBV vaccine available to all HCWs and the vaccination process is ongoing.

In our study, only $45.8 \%$ of the healthcare providers were wearing gloves at the time of injury. A study in Iran showed that around $74 \%$ were using gloves when they experienced NSIs. ${ }^{26}$ Another study in India showed that around 39\% were not wearing gloves at the time of NSIs. ${ }^{21}$

Cleaning the injury site with soap and water was the most frequently used first- aid measure following exposure in over $75 \%$ of HCWs injured. The correct method of washing the injury site was practiced by 
majority of doctors \& nursing staff while nursing students \& hospital waste disposal staff showed poor knowledge about immediate action following exposure (Table $1-4)$.

Table.1 Distribution of NSI according to the category of staff

\begin{tabular}{|l|l|l|}
\hline STAFF CATEOGRY & No. & Percentage \\
\hline Nurses & 15 & 31.2 \\
\hline Nursing students & 13 & 27.1 \\
\hline Lab Technicians & 8 & 16.7 \\
\hline Doctors & 5 & 10.4 \\
\hline Hospital waste disposal staff & 4 & 8.3 \\
\hline Hospital attendants & 2 & 4.2 \\
\hline Pharmacist & 1 & 2.1 \\
\hline
\end{tabular}

Table.2 Place of occurrence of NSI

\begin{tabular}{|l|l|l|}
\hline PLACE OF OCCURRENCE & No. & Percentage \\
\hline Wards & 16 & 33.3 \\
\hline Emergency Department & 11 & 22.9 \\
\hline Intensive Care Unit & 8 & 16.7 \\
\hline Laboratory & 6 & 12.5 \\
\hline Operation theatre & 4 & 8.3 \\
\hline Out patient Department & 2 & 4.2 \\
\hline Others & 1 & 2.1 \\
\hline
\end{tabular}

Table.3 Cause of the NSI

\begin{tabular}{|l|l|l|}
\hline CAUSE OF NSI & No. & Percentage \\
\hline During Procedure & 35 & 73 \\
\hline Improper Disposal & 9 & 18.7 \\
\hline Recapping & 4 & 8.3 \\
\hline
\end{tabular}

Table.4 Device leading to needle stick injuries

\begin{tabular}{|l|l|l|}
\hline DEVICE & No. & Percentage \\
\hline Syringe needle & 20 & 41.7 \\
\hline Lancet & 14 & 29.2 \\
\hline IV cannula & 6 & 12.5 \\
\hline Suture needle & 5 & 10.4 \\
\hline Blade & 3 & 6.2 \\
\hline
\end{tabular}

In conclusion, preventing NSIs is the most effective way to protect healthcare providers from the infectious diseases that are transmitted by accidents due to injury by needle. There is a need of HCW's to adopt safe practices, use safety-engineered devices, institute safe systems of work and promote adherence to standard infection control 
procedures. Hence, continuing awareness programs, education and training is needed to inculcate safe practice habits during healthcare service by the HCW's. Continuous education of all categories of health care workers plays a crucial role in capturing NSI. Staff should be encouraged to self-report without any delay and should treat each NSI as an emergency. As hospitals are subjected to a large amount of staff attrition and recruitment a robust induction and in-service programme forms the backbone for NSI reporting and prevention of NSI amongst health care workers.

\section{References}

1. Norsayani MY, Noor Hassim I. Study on incidence of needle stick injury and factors associated with this problem among medical students. J Occup Health 2003; 45: 172- 8 .

2. Spruce L. Back to Basics: Sharps Safety. AORN J 2016; 104:30- 6.

3. Lee JM, Botteman MF, Xanthakos N, Nicklasson L. Needlestick injuries in the United States. Epidemiologic, economic, and quality of life issues. AAOHN J 2005; 53: 117- 33.

4. Goel V, Kumar D, Lingaiah R, Singh S. Occurrence of needlestick and injuries among health-care workers of a Tertiary Care Teaching Hospital in north India. J Lab Physicians 2017; 9: 20- 5 .

5. Au E, Gossage JA, Bailey SR. The reporting of needle stick injuries sustained in theatre by surgeons: Are we under- reporting? J Hosp Infect 2008;70:66- 70 .

6. Wilburn SQ, Eijkemans G. Preventing needlestick injuries among healthcare workers: A WHO-ICN collaboration. Int J Occup Environ Health 2004; 10: 451-6.

7. Singh S, editor. Standard operative manual:
Hospital infection control. New Delhi: National AIDS Control Organization, Government of India; 1999.

8. Radha R, Khan A. Epidemiology of needle stick injuries among the healthcare workers of a rural tertiary care hospital - A cross- sectional Study. Nat J Community Med 2012; 3: 589- 94.

9. Kermode M, Jolley D, Langkham B, Thomas MS, Crofts N. Occupational exposure to blood and risk of bloodborne virus infection among health care workers in rural north Indian health care settings. Am J Infect Control 2005; 33: 34- 41.

10. Sultana A, Kulsoom A, Iqbal R. Needle stick/sharps injuries in health care workers. JRawalpindi Med Coll 2014; 18: $133-5$.

11. Ebrahimi H, Khosravi A. Needle stick injuries among nurses. J Res Heal Sci 2007; 7: 56- 62.

12. Alam, M. Knowledge, attitude and practices among health care workers on needle- stick injuries. Ann Saudi Med 2002; 22: 396- 9.

13. Pournaras S, Tsakris A, Mandraveli K, Faitatzidou A, Douboyas J, Tourkantonis A, et al. Reported needle stick and sharp injuries among health care workers in a Greek general hospital. Occup Med 1999; 49: 423-6.

14. Mbaisi EM, Ng'ang'a Z, Wanzala P, Omolo J. Prevalence and factors associated with percutaneous injuries and splash exposures among health- care workers in a provincial hospital, Kenya, 2010. Pan Afr Med J 2013; 14:10.

15. Wood AJ, Nadershahi NA, Fredekind RE, Cuny EJ, Chambers DW. Student occupational exposure incidence: Perception versus reality. J Dent Educ 2006; 70: 1081- 8.

16. Singru SA, Banerjee A. Occupational 
exposure to body fluids among health care workers in a teaching hospital in Mumbai, India. Indian J Community Med 2008; 33: 26-30.

17. Evans B, Duggan W, Baker J, Ramsay M, Abiteboul D. Exposure of health care workers in England, Wales, and the Northern Ireland to blood borne viruses between July 1997 and June 2000: analysis of surveillance data. BMJ 2001; 322: 397-8.

18. Sharma R, Rasania S, Verma A, Singh S. Study of prevalence and response to needle stick injuries among health care workers in a tertiary care hospital in Delhi, India. Indian J Community Med 2010; 35: 74- 7.

19. Cervini P, Bell C. Brief report: Needlestick injury and inadequate post- exposure practice in medical students. J Gen Intern Med 2005; 20: 419- 21.

20. Muralidhar S, Singh PK, Jain RK, Malhotra M, Bala M. Needle stick injuries among health care workers in a tertiary care hospital of India. Indian J Med Res 2010;131: 405- 10.

21. Radha R, Khan A. Epidemiology of needle stick injuries among the healthcare workers of a rural tertiary care hospital - A cross- sectional Study. Nat J Community Med 2012; 3: 589- 94.

22.International Health Care Workers Safety Center. Exposure prevention information network (EPI net) Data reports; Charlottesville: University of Virginia; 1999. p. 97.

23. Salelkar S, Motghare DD, Kulkarni MS, Vaz FS. Study of needle stick injuries among health care workers at a tertiary care hospital. Indian J Public Health 2010;54:18- 20.

24. Singhal V, Bora D, Singh S. Hepatitis B in health care workers: Indian scenario. J Lab Physicians 2009; 1: 41- 8 .

25. Hutin Y, Hauri A, Chiarello L, Catlin M, Stilwell B, Ghebrehiwet T, et al. Best infection control practices for intradermal, subcutaneous, and intramuscular needle injections. Bull World Health Organ 2003; 81: 491- 500

26. Askarian M, Shaghaghian S, Mclaws Ml. Needlestick injuries among nurses of Fars Province, Iran. Ann Epidemiol 2007; 17: 988- 92.

\section{How to cite this article:}

Lyra, P.R., Vivek Hittinahalli, Sangeetha, K.T. 2019. Study of Needle Stick Injuries among Health Care Workers at a Tertiary Care Hospital. Int.J.Curr.Microbiol.App.Sci. 8(07): 11341140. doi: https://doi.org/10.20546/ijcmas.2019.807.134 